\title{
ПРОГРЕССИВНЫЙ АЛЬЯНС СОЦИАЛИСТОВ И ДЕМОКРАТОВ: АКТУАЛЬНЫЕ ПРОБЛЕМЫ МИРОВОЙ ПОЛИТИКИ
}

\begin{abstract}
Аннотация. Европейский парламент является законодательным органом Евросоюза. В его заседаниях участвуют различные политические группы депутатов. Они объединяются во фракции по партийной принадлежности. Соблюдение этого принципа требует разработки политической стратегии, которую принимают и разделяют все представители фракции. Среди политических групп, входящих в восьмой состав Европарламента, Прогрессивный альянс сочиалистов и демократов является одним из старейших. В настоящее время сокращается количество тех, кто верит в идею единой Европы. Популярным стал евроскептицизм отрицание реального воплощуения идеи интеграции. В статье рассматриваются причины этого явления, а также отношение к нему представленного в Европарламенте Прогрессивного альянса социалистов и демократов, их взгляды на политику санкиий, взаимоотношения России, ЕС и США.
\end{abstract}

Ключевые слова: Прогрессивный альянс сочииалистов и демократов, евроскептицизм, санкиии, интеграция, Евросоюз, безопасность, вызов.

Прогрессивный альянс социалистов и демократов (ПАСД) занимает второе место в Европарламенте (ЕП) по количеству депутатов (190). Больше только у консерваторов и христианских демократов - 213 (Европейская народная партия). В таком составе Европарламент остаётся до мая 2019 г. Аналитики заметили, что в последнее время набирают силу крайне правые и националистические партии, но это не является свидетельством резкой смены вектора развития, а скорее характеризует степень недовольства осуществляемой сегодня политикой.

Прогрессивный альянс защищает права потребителей, изучает вопросы устойчивого развития, ставит вопрос о необходимости финансовых реформ с единственной целью - сделать Европу демократичной в полном смысле этого слова. Однако сегодня всё меньше и меньше людей верят в основополагающие идеи Евросоюза. Соответственно, на него возлагается меньше надежд. У представителей фракции свои взгляды на политику санкций, взаимоотношения России, ЕС и США и будущее современной дипломатии. Эти взгляды за последние три года изменились лишь незначительно, а вот проблем у всех участников взаимодействия стало заметно больше.

\section{Оценка Альянсом внешней политики США}

8-9 июня 2018 г. в Канаде проходил саммит G7. Президент США Дональд Трамп заявил, что Россию стоит вернуть в состав «большой семёрки».

Предложение прозвучало неожиданно как, например, для Германии - канцлер Ангела Меркель напомнила о несоответствии России критериям членства в G7, так и для самой Рос-

\footnotetext{
(C) Башаримов Юрий Петрович - кандидат исторических наук, доцент кафедры «Информатика, математика и общегуманитарные науки» Липецкого филиала Финансового университета при Правительстве РФ. Aдpec: 398050, Россия, г. Липецк, ул. Интернациональная, д. 12б. E-mail: yurybasharimov@yandex.ru.
}

DOI: http://dx.doi.org/10.15211/vestnikieran220198591 
сии, признавшей формат таких встреч неэффективным.

Лидер Прогрессивного альянса Удо Булман сравнил точку зрения Трампа с погодой: и то и другое постоянно меняется. Действия президента США трудно предсказать, а это, по мнению Булмана, означает, что Евросоюзу следует быть как никогда сплочённым. Только сотрудничество государств позволит сохранить международные ценности.

Этот тезис подтверждается реальными действиями: летом 2018 г. представители Альянса совершили четырёхдневную поездку в США, где прошла встреча с конгрессменами как демократами, так и республиканцами. В мероприятии также принимали участие бизнесмены, члены научных сообществ и торговых союзов. Основными темами обсуждения стали международная торговля, обеспечение национальной безопасности, изменение климата и политическая ситуация в Соединённых Штатах и Евросоюзе. Виктор Бостинару, вице-президент ПАСД, заявил, что каждая такая встреча позволяет сблизить государства по обе стороны Атлантического океана ${ }^{1}$.

Для западной модели демократии наступили кризисные времена. Страны, которые предпочитают держаться в стороне, вряд ли смогут самостоятельно решить эту проблему. И всётаки нужно учитывать специфику конкретного государства. Так, по мнению Бостинару, президент США не всегда осуществляет последовательную политику. Целью партнёров США должно быть тесное взаимодействие с Конгрессом в интересах демократии, свободы, устойчивой торговли. Одновре́менно следует вести борьбу с популизмом.

Результатом встречи стало решение провести в 2019 г. «трансатлантическую неделю». Это позволит укрепить связи с представителями прогрессивных сил США. Можно отметить, что члены Прогрессивного альянса по-прежнему стремятся к диалогу с теми, кто разделяет их ценности. Но какая роль в установлении контактов с трансатлантическими партнёрами отведена Дональду Трампу?

В Финляндии (16 июля 2018 г., Хельсинки) состоялся саммит глав США и России. Руководитель ПАСД, комментируя итоги встречи, отметил, что у президентов двух стран много общего: каждый пытается презентовать мероприятие с лучшей стороны, даже если результаты этого мероприятия являются скромными.

У. Булман назвал политику Путина и Трампа риском для Европы, которая не привыкла к непредсказуемости. Оба президента «пытаются расшатать западные демократии». Булман добавил, что до выборов Трампа Америка была для ЕС надёжным партнёром, «а сегодня Трамп почему-то называет нас врагами, хотя причин для этого нет. Рассматривать это как изменение политической стратегии нет смысла. Нельзя позволить таким людям, как Путин и Трамп, обесценить категории демократии и свободы. Для Европы это вызов»².

Примерно в то же время президент США встретился с председателем Еврокомиссии Жан-Клодом Юнкером. ПАСД оценил влияние этой встречи на трансатлантическое партнёрство как положительное, но отказался признать ситуацию в целом благоприятной.

С одной стороны, Европа «была освобождена» от дальнейшей эскалации конфликта в сфере торговли. В то же время США так и не урегулировали вопрос изменения таможенных пошлин на сталь и алюминий. Фракция социалистов демократов в Европейском парламенте снова заверила своих сторонников, что её целью является защита интересов европейской промышленности и рабочих.

\footnotetext{
1 В Канаде завершился саммит G7. Новая газета [Электронный ресурс]. URL: https://www.novayagazeta.ru/ news/2018/06/10/142383-v-kanade-zavershilsya-sammit-g7/ (дата обращения: 03.08.2018).

${ }^{2}$ Czerny-Grimm, Inga. Strong transatlantic dialogue with progressive forces is more important than ever. 20.07.2018. URL: http://www.socialistsanddemocrats.eu/newsroom/strong-transatlantic-dialogue-progressive-forces-more-import ant-ever/ (accessed on: 04.08.2018).
}

Научно-аналитический вестник ИЕ РАН, 2019, №2 
После завершения саммита НАТО (11-12 июля 2018 г., Брюссель) лидер Прогрессивного альянса У. Булман заявил, что уровень безопасности в мире не повысится, пока во главе США будет стоять человек, выступающий за увеличение расходов на вооружение и игнорирующий интересы партнёров.

По мнению Булмана, Европа в своём стремлении обеспечить защиту жителей разных стран идёт другим путём. ЕС не видит необходимости в финансировании всё большего количества разработок в сфере военной промышленности. Она предлагает инвестировать в экономическое, политическое, социальное развитие, публичную дипломатию, кооперацию. Не обращать внимания на такие международные организации, как НАТО и ООН, считает Булман это тупиковый вариант. В настоящее время главной угрозой стабильности является заразительная для Европы модель политики Трампа.

Польша и Венгрия уже начали заимствовать некоторые механизмы, подрывающие основы демократии. Представители политических кругов Австрии, Германии, Италии играют на человеческих слабостях, чтобы получить как можно больше голосов. Часто они пропагандируют ксенофобию. В этой ситуации Европа должна иметь целью борьбу с популизмом и националистическими идеями.

Прогрессивный альянс социалистов и демократов ожидает от Д. Трампа возвращения к логически обоснованной и последовательной политике, соблюдению интересов разных категорий населения. Нельзя забывать о ст. 5 Устава НАТО, подтверждающей, что любая попытка военного вмешательства в дела одной из европейских стран встретит сопротивление всего альянса.

В июне 2018 г. делегация ПАСД побывала в США в рамках встречи по вопросам защиты прав граждан. Участники поделились мнениями о том, что администрация Трампа всё меньше значения придаёт партнёрским отношениям с ЕС.

Политику отделения детей мигрантов от родителей на границе США с Мексикой они назвали бесчеловечной и незаконной с точки зрения международного права. Какой смысл вкладывал Трамп в свой предвыборный лозунг: «Сделаем Америку снова великой»? Значило ли это возвращение к тем временам, когда женщины, дети и представители меньшинств имели ограниченный доступ к своим правам? В таком случае поводов для оптимизма у Евросоюза просто нет.

Проблема мигрантов была озвучена в 2017 г. в докладе Альянса: социал-демократы заявили, что политика нового президента выглядит пугающей для всего цивилизованного мира. Не успела пройти неделя со дня инаугурации, как Трамп расстроил диалог с государствами Латинской Америки, Мексикой, Ближним Востоком. Эта тенденция угрожает развитию трансатлантических отношений ${ }^{1}$.

Впрочем, лидер социал-демократов в Европарламенте У. Булман видит угрозу для социальной справедливости и в других проектах, так или иначе связанных с политикой США. Например, бывший советник президента Америки Стивен Бэннон не так давно предложил создать на территории Европы политический фонд для формирования и поддержки фракции правых в Европейском парламенте. Булман резюмировал: такой проект - не что иное как атака на европейскую демократию.

Д. Трамп и С. Бэннон сегодня не поддерживают действия друг друга. Отсюда следует вывод: Прогрессивный альянс выступает не против конкретного человека, будь то президент, его бывший советник по стратегическим вопросам или третье лицо, а против решений, кото-

\footnotetext{
${ }^{1}$ Швейцер В.Я. Партия и движения политической альтернативы современной Европы. Научно-аналитический вестник Института Европы РАН, №3, 2018. С. 43-47.
}

Научно-аналитический вестник ИЕ РАН, 2019, №2 
рые могут представлять угрозу для ценностей ЕС.

\section{Дифференцированное отношение Альянса к политике санкций}

Вернёмся к вопросу о санкциях. Члены Альянса относятся к этой проблеме по-разному - в зависимости от того, какая страна и по какой причине становится объектом ограничений. Такую политику либо одобряют, либо осуждают.

Так, в конце 2017 г. президент Альянса Джанни Питтелла, говоря о формировании коалиционного правительства в Австрии, подчеркнул, что распространение подобной тенденции может иметь серьёзные последствия для всей Европы, «если ключевые ценности ЕС будут находиться под угрозой, то можно будет допустить ужесточение политики вплоть до введения санкций»» ${ }^{1}$

В чём суть претензий к Себастьяну Курцу, канцлеру Австрии? Глава Альянса замечает, что правительству Австрии, коалиции консерваторов и националистов следовало бы сделать своим приоритетом обеспечение высокого уровня жизни европейцев. Курц должен доказать, что он не просто говорит о своей проевропейской позиции, а подтверждает её реальными действиями. Со стороны канцлера было бы неразумным позволять националистам из Партии Свободы (FРӦ) подрывать основы идентичности населения ЕС.

На официальном сайте Альянса опубликовано заявление вице-президента В. Бостинару о ситуации в Корее: «Кажется, напряжение ослабевает. Этому в немалой степени способствовало проведение Зимних Олимпийских игр. Но мы должны в первую очередь быть благодарны мировому сообществу, которое неоднократно осуждало милитаристскую политику Северной Кореи. Велика роль Евросоюза в этом процессе. Мы ввели достаточно ограничений, и со временем ситуация улучшилась. Но ослаблять давление ещё рано: нужно дождаться момента объявления Кореи зоной, свободной от ядерного оружия» ${ }^{2}$.

Альянс приветствовал первую встречу Ким Чен Ына и Д. Трампа в Сингапуре: прямой диалог - один из лучших способов снизить уровень международной напряжённости. От конфронтации страны перешли к совместному обсуждению проблем. Однако если бы Трамп не вышел из Иранской ядерной сделки, уровень доверия к нему Северной Кореи вырос бы.

Вполне естественно, что Прогрессивный альянс выступает против санкций в отношении европейских компаний со стороны Америки. Обсуждение этого вопроса в Европарламенте связано в первую очередь с выходом США из иранской ядерной сделки.

«Что это, как не демонстрация амбиций в рамках предвыборной кампании? Ведь иранская сделка подтвердила свою эффективность. Мы поддерживаем чёткую позицию Еврокомиссии и решения, предполагающие защиту европейских организаций», - заявляют социалдемократы $^{3}$. ЕС стремится сохранить своих партнёров по бизнесу и поэтому допускает продолжение финансирования Ирана Европейским инвестиционным банком.

Проблемной ситуацией для ЕС в целом является положение дел в Польше. Еврокомиссия обвиняет власти страны в нарушении законов Евросоюза: в 2017 г. среди законодательных инициатив Польши оказалось предоставление Сейму права назначать замену судьям Национального судебного совета. Это вызвало недовольство Европарламента и стало поводом для обсуждения возможности применения санкций.

\footnotetext{
${ }^{1}$ Савино Д. Европеизм или национализм? Россия в глобальной политике. 10.04.2018. URL: http://www.globalaf fairs.ru/number/Evropeizm-ili-natcionalizm-19485/ (дата обращения: 06.08.2018).

${ }_{2}^{2}$ Czerny-Grimm, Inga. Historic meeting between Trump and Kim, but whether it goes beyond the photo-ops remains to be seen. 12/06/2018. URL: http://www.socialistsanddemocrats.eu/newsroom/historic-meeting-between-trump-and-kimwhether-it-goes-beyond-photo-ops-remains-be-seen/ (accessed on: 05.08.2018).

${ }^{3}$ Савино Д. Там же.
} 
В 2018 г. ситуация повторилась: ПАСД дал отрицательную характеристику новому закону Польши, предполагающему ликвидацию 40\% должностей в Верховном Суде. Лидер Альянса У. Булман заявил, что в этом случае вряд ли можно вообще говорить о демократии, независимой юстиции, принципе разделения властей. Верховный Суд был «последним бастионом демократии» на территории страны. Теперь же десятки судей вынуждены будут уйти с работы.

Руководитель фракции социал-демократов в Европарламенте снова высказался в поддержку применения ст. 7 Договора о ЕС. Статья имеет второе название «ядерный удар». Она предусматривает наказание членов Евросоюза, допустивших нарушение фундаментальных правил. Государство-нарушителя можно лишить права голоса в Совете Европы. Это и предлагает сделать Булман. «Нужно быть уверенными, что права жителей Польши и всех граждан ЕС на жизнь в свободном, открытом, демократическом обществе соблюдаются в полном объёме» ${ }^{1}$.

Альянс традиционно поддерживает идею единого пространства. В 2016 г. фракция выступила за успешное завершение визовой либерализации между Грузией и Евросоюзом. Во время августовского конфликта 2008 г. фракция приняла сторону Грузии и заявила о том, что Россия «оккупировала Абхазию и Южную Осетию - фактически 20\% территории Грузии».

Социал-демократическая фракция в Европарламенте имеет целью поддержку улучшения отношений между Абхазией, Южной Осетией и «остальной частью Грузии». Страна стала сильнее, чем десять лет назад. Сегодня это достойный восточный партнёр Евросоюза. «Хотелось бы, чтобы Россия не забывала о своих международных обязательствах»².

\section{Отношение Альянса к России}

Отношение представителей Прогрессивного альянса социалистов и демократов к России меняется незначительно в зависимости от положения дел на международной политической арене. Например, «дело Скрипалей» рассматривается некоторыми представителями фракции как одно из доказательств использования Россией химического оружия. Это очередной повод для пересмотра стратегии обеспечения безопасности.

Главное - «не бояться оказывать сопротивление» Владимиру Путину, который, по словам депутата Европарламента Аны Гомеш, «любит лезть на рожон». Другой депутат Йеппе Кофод отмечает вероятность влияния Москвы на западные демократии (процесс выборов в Америке, брекзит и, возможно, выборы в Европарламент).

Войну в Сирии члены Альянса рассматривают как источник бесконечного страдания миллионов людей. Евросоюзу следовало бы не только поставлять гуманитарную помощь, но и играть более заметную роль в деле мирного урегулирования конфликта. «Нельзя позволить России, Ирану и Асаду решать судьбу Сирии без привлечения мирового сообщества», - считают социал-демократы ${ }^{3}$.

Неоднозначное отношение Прогрессивного альянса к политике России сохраняется как минимум с 2013-2014 гг., когда начался конфликт на Украине. В то время Пётр Порошенко встречался с лидером ПАСД Д. Питтелла. Последний заявил, что Альянс поддержит решительные действия ЕС в случае, если мирное урегулирование конфликта окажется недостижимым.

Депутаты Европарламента от Прогрессивного альянса поддерживают политику П. По-

\footnotetext{
${ }^{1}$ Савино Д. Там же.

${ }^{2}$ Czerny-Grimm, Inga. 10 years after Russian invasion, we remain committed to sovereignty and territorial integrity of Georgia. 14.06.2018. URL: http://www.socialistsanddemocrats.eu/newsroom/10-years-after-russian-invasion-we-rema in-committed-sovereignty-and-territorial-integrity/ (accessed on: 05.08.2018).

${ }^{3}$ Савино Д. Европеизм или национализм? Там же.
} Научно-аналитический вестник ИЕ РАН, 2019, №2 
рошенко и считают присоединение Крыма к России аннексией, которая противоречит международному праву.

В марте 2018 г., когда власти Украины приняли решение запретить гражданам РФ посещать избирательные участки во время президентских выборов, один из членов Прогрессивного альянса посчитал такую реакцию «ненадлежащей». Однако он заметил, что в «чрезвычайной ситуации» спорные решения допустимы.

Также Альянс уверен, что некоторые российские СМИ распространяют ложные сведения. Об этом на одном из заседаний заявил представитель фракции социал-демократов в Европарламенте Юджин Фрейд. Он назвал конкретные средства массовой информации: «Спутник», «Russia Today». Как полагает член Альянса, Европа должна уметь защищать себя, в том числе от хакерских атак.

Означает ли всё это, что Прогрессивный альянс и Россия в принципе не могут найти общий язык? Вряд ли. По мнению многих историков и политологов, британских лейбористов критиковали ещё в Советском Союзе ${ }^{1}$. Считалось, что они - «соглашатели», их деятельность необходима для контроля рабочего движения. Как ни парадоксально, когда у власти оказывались лейбористы, отношения с Великобританией улучшались - по крайней мере, пока не появилось новое поколение, готовое проводить американскую модель политики. А ведь именно представители этой возрастной категории составляют значительную часть Альянса.

\section{Некоторые выводы}

Анализируя вышеизложенные позиции Альянса следует, прежде всего, иметь ввиду, что на сегодня социал-демократия Европы выглядит наиболее слабым звеном среди других политических течений Евросоюза. Христианские демократы, консерваторы, либералы, зелёные теряют голоса на национальных выборах, однако они по-прежнему сохраняют свои позиции в органах исполнительной власти. В отличие от них, если иметь ввиду страны Западной Европы, то партии, входящие в ПАСД, оказались в оппозиции в Великобритании, Финляндии, Дании, Нидерландах, Франции, Италии, Австрии, Греции. С трудом они сохраняют свои позиции в высшем эшелоне государственной власти в Португалии, Испании. Неясны их перспективы в Швеции и Бельгии. Скорее всего, выборы в Европарламент в мае 2019 г. подтвердят эти тенденции. Отсюда и неопределённость и неконструктивность взглядов ПАСД по широкому кругу международных проблем.

\section{Список литературы}

В Канаде завершился саммит G7. Новая газета [Электронный ресурc]. URL: https://www. novayagazeta.ru/news/2018/06/10/142383-v-kanade-zavershilsya-sammit-g7/ (дата обращения: 03.08.2018).

Куприянов А. Есть ли у России друзья среди европейских социалистов. 17.09.2015. URL: https://lenta.ru/articles/2015/09/16/labours/ (дата обращения: 05.08.2018).

Савино Д. Европеизм или национализм? Россия в глобальной политике. 10.04.2018. URL: http://www.globalaffairs.ru/number/Evropeizm-ili-natcionalizm-19485/ (дата обращения: 06.08. 2018).

Швейцер В.Я. Час евроскептиков? В сб.: Электоральные процессы в Европейском союзе (середина второго десятилетия ХХІ века). ИЕ РАН. М., 2016. С. 7-11.

Швейцер В.Я. Партия и движения политической альтернативы современной Европы. На-

\footnotetext{
${ }^{1}$ Куприянов А. Есть ли у России друзья среди европейских социалистов. 17.09.2015. URL: https://lenta.ru/artic les/2015/09/16/labours/ (дата обращения: 05.08.2018).
} 
учно-аналитический вестник Института Европы РАН, №3, 2018. С. 43-47.

\section{References}

Czerny-Grimm, Inga. 10 years after Russian invasion, we remain committed to sovereignty and territorial integrity of Georgia. 14.06.2018. URL: http://www.socialistsanddemocrats.eu/newsroom /10-years-after-russian-invasion-we-remain-committed-sovereignty-and-territorial-integrity/ (accessed on: 05.08.2018).

Czerny-Grimm, Inga. Historic meeting between Trump and Kim, but whether it goes beyond the photo-ops remains to be seen. 12.06.2018. URL: http://www.socialistsanddemocrats.eu/newsroom/ historic-meeting-between-trump-and-kim-whether-it-goes-beyond-photo-ops-remains-be-seen/ (accessed on: 05.08.2018).

Czerny-Grimm, Inga. Strong transatlantic dialogue with progressive forces is more important than ever. 20.07.2018. URL: http://www.socialistsanddemocrats.eu/newsroom/strong-transatlanticdialogue-progressive-forces-more-important-ever/ (accessed on: 04.08.2018).

Kupriyanov A. Est" li u Rossii druz'ya sredi evropejskix socialistov. 17.09.2015. URL: https://lenta.ru/articles/2015/09/16/labours/ (data obrashheniya: 05.08.2018).

Savino D. Evropeizm ili nacionalizm? Rossiya v global'noj politike. 10.04.2018. URL: http:// www.globalaffairs.ru/number/Evropeizm-ili-natcionalizm-19485/ (data obrashheniya: 06.08.2018).

Shvejcer V.Ya. Chas evroskeptikov? V sb.: Elektoral'nye processy v Evropejskom soyuze (seredina vtorogo desyatiletiya XXI veka). IE RAN, M., 2016. S. 7-11.

Shvejcer V.Ya. Partiya i dvizheniya politicheskoj al'ternativy sovremennoj Evropy. Nauchnoanaliticheskij vestnik Instituta Evropy RAN, №3, 2018. S. 43-47.

V Kanade zavershilsya sammit G7. Novaya gazeta [E'lektronnyj resurs]. URL: https://www.nov ayagazeta.ru/news/2018/06/10/142383-v-kanade-zavershilsya-sammit-g7/ (data obrashheniya: 03.08.2018).

\section{Progressive Alliance of Socialists and Democrats: the Actual Problems of the World Policy}

Author. Yuri Basharimov, Candidate of Sciences (History), associate Professor of «Informatics, mathematics and General Humanities». Financial University under the government of the Russian Federation, Lipetsk branch. Address: 12b, International street, Lipetsk city, Russia, 398050. E-mail: yurybasharimov@yandex.ru.

Abstract. The European Parliament acts as the legislative and representative body of the European Union. Political groups of deputies participate in its meetings. They are United into factions by party affiliation. Compliance with this principle requires the development of a political strategy, which is accepted and shared by all members of the faction. Among the political groups that make up the eighth European Parliament, the Progressive Alliance of socialists and Democrats is one of the oldest: it has existed since 1953 under different names. Currently, fewer and fewer people believe in the idea of the European Union. Popular today is a testimony to the denial of the idea of integration. The article discusses the causes of this phenomenon, as well as the attitude of the Progressive Alliance of socialists and Democrats represented in the European Parliament and their views on the policy of sanctions, the relationship between Russia, the EU and the United States.

Key words: Progressive Alliance of socialists and Democrats, euroscepticism, sanctions, integration, EU, security, challenge.

DOI: http://dx.doi.org/10.15211/vestnikieran220198591

Научно-аналитический вестник ИЕ РАН, 2019, №2 